\title{
Peripheral Nerve Sheath
}

National Cancer Institute

\section{Source}

National Cancer Institute. Peripheral Nerve Sheath. NCI Thesaurus. Code C12972.

The protective covering surrounding the axon of neurons in the peripheral nervous system. 